\title{
Reološka svojstva salatne majoneze s dodatkom pulpe kivija
}

Tihomir Moslavac ${ }^{1}$, Ante Pazman'2, Tajana Vukina'2, Mario Jakobović2

\section{SAŽETAK}

U ovom radu istraživan je utjecaj procesnih parametara homogenizacije i tip sustava rotor/stator na reološka svojstva salatne majoneze s dodatkom pulpe kivija. Također, ispitivan je utjecaj sastava salatne majoneze na promjenu reoloških svojstava. Uljnu fazu salatne majoneze čini mješavina rafiniranog suncokretovog ulja i hladno prešanog bučinog ulja. Od ugljikohidrata korišteni su glukoza, saharoza i maltodekstrin. Mliječnu komponentu salatne majoneze čini punomasno mlijeko, sirutka i kazein. Uzorci salatne majoneze pripremljeni su sa svježim žumanjkom jajeta kokoši. Proces homogenizacije salatne majoneze proveden je kod raznih brzina rotora te vremena izrade majoneze. Mjerenje reoloških svojstava provedeno je na rotacijskom viskozimetru pri temperaturi $25^{\circ} \mathrm{C}$. Iz dobivenih rezultata istraživanja izračunati su reološki parametri koeficijent konzistencije, indeks tečenja i prividna viskoznost. Rezultati istraživanja su pokazali da procesni parametri homogenizacije kao i pojedini sastojci salatne majoneze utječu na njena reološka svojstva. Korištenjem sirutke u prahu i šećera saharoze dobivene su veće vrijednosti reoloških parametara koeficijenta konzistencije i prividne viskoznosti, a manji indeks tečenja.

Ključne riječi: salatna majoneza, reološka svojstva, proces homogenizacije, sastojci majoneze, pulpa kivija

\section{UVOD}

Majoneza je prehrambeni proizvod koji je široko konzumiran, jedan od najčešće korištenih umaka u svijetu (Cristina, 2005). Predstavlja polučvrstu emulziju ulje/voda pripremljenu emulgiranjem biljnog ulja sa ostalim sastojcima kao što su žumanjak jajeta, ocat, senf. Žumanjak jajeta je vrlo važan za stabilnost ovog proizvoda (Hasenhuettl, 2008; Narsimhan i Wang, 2008). Salatna majoneza prema Pravilniku (1999) mora sadržavati minimalno 50 \% biljnog ulja koji čini uljnu fazu proizvoda. Jestivo biljno ulje ima važnu ulogu u stvaranju ovog tipa emulzije proizvoda, doprinosi okusu, izgledu, teksturi te oksidacijskoj stabilnosti na vrlo specifičan način (McClements i Demetriades, 1998). Korištenjem različitih vrsta biljnih ulja u kombinaciji postiže se željeni sastav masnih kiselina i tokoferola koji imaju funkciju prirodnih antioksidanasa te se mogu poboljšati prehrambena i senzorska svojstva majoneze (Kostyra i Barylko-Pikielna, 2007). Izradom salatne majoneze sa uljnom fazom koju čini mješavina suncokretovog ulja (obogaćuje proizvod esencijalnom linolnom masnom kiselinom) i hladno prešanog bučinog ulja sa oleinskom masnom kiselinom i gama tokoferolom doprinose većoj stabilnosti majoneze prema oksidacijskom kvarenju. Hladno prešano bučino ulje svojom aromom i bojom doprinosi senzorskim svojstvima salatne majoneze. Dodatkom luteina, fikocijanina i drugih spojeva (Batista, 2006), procesirane cikle (Raikos, 2016) te voćne komponente (pulpa)

1 Prof. dr. sc. Tihomir Moslavac, Prehrambeno-tehnološki fakultet Sveučilište Josipa Jurja Strossmayera Osijek, Franje Kuhača 20, 31000 Osijek, Hrvatska

2 Ante Pazman - student; Tajana Vukina - student; Mario Jakobović, dipl. ing. v. pred., Veleučilište u Požegi, Vukovarska ul. 17, Požega, Hrvatska 
postiže se oksidacijska stabilnost te specifičan okus i boja majoneze koja potiče zanimanje potrošača prema novim okusima, novim proizvodima. Reološka svojstva značajan su čimbenik kvalitete hrane (Mezger, 2002) tako i proizvoda koji predstavljaju emulziju ulje/voda (majoneze, umaci). Poznavanje reoloških svojstava ovih proizvoda značajno je kod kreiranja određene viskoznosti i konzistencije salatne majoneze (Štern i sur., 2001; Wendin i Hall, 2001), u kontroli kvalitete tijekom proizvodnje, skladištenja i transporta (Juszczak i sur., 2003). Kvaliteta ovih proizvoda, kao i njihova viskoznost i stabilnost ovisi o $\mathrm{pr}^{\circ} \mathrm{Cesu}$ homogeniziranja (Wendin i sur.,1999), raspršenosti i dispergiranosti kapljica ulja u vodenoj kontinuiranoj fazi majoneze, žumanjku jajeta (Guilmineau i Kulozik, 2007; Xiong i sur., 2000; Laca i sur., 2010), vrsti ugljikohidrata (Ruiling i sur., 2011) te udjelu i vrsti mliječne komponente (Dybowska, 2008). U ovim emulzijama kapljice ulja su mehaničkim postupkom dispergirane u kontinuiranoj vodenoj fazi octa te se djelovanjem prirodnog emulgatora iz žumanjaka jajeta postiže veća stabilizacija cijelog sustava (Kiosseoglou, 2003; Castellani i sur., 2006). Tijekom formiranja emulzije važnu ulogu imaju procesni parametri homogenizacije te izbor rotor/stator sustava kojim se formiraju kapljice uljne faze većeg ili manjem promjera što rezultira različitom stabilnosti emulzije. Reološko ponašanje salatne majoneze neprestano se istražuje budući da utječe na stav potrošača sastavom, konzistencijom, okusom ali i primjenom na salate, pomfrit i druga jela (Franco i sur., 1995; Akhtar i sur., 2005; Abu-Jdayil, 2003).

$\mathrm{U}$ ovom radu istraživan je utjecaj procesnih parametara homogenizacije (brzina rotora, vrijeme trajanja izrade majoneze) i tip sustava rotor/stator na reološka svojstva salatne majonez̄e kod temperature mjerenja $25^{\circ} \mathrm{C}$. Također, ispitivan je utjecaj sastava salatne majoneze (mliječna komponenta, vrsta ugljikohidrata) na promjenu reoloških svojstava pri temperaturi $25^{\circ} \mathrm{C}$.

\section{MATERIJAL I METODE}

Materijali koji su korišteni za izradu salatne majoneze s dodatkom pulpe kivija su:

- Uljna faza 70 \% (rafinirano suncokretovo ulje 60 \% i hladno prešano bučino ulje $10 \%$ )

- Žumanjak jajeta kokoši 7 \%

- Ugljikohidrati: saharoza, glukoza i maltodekstrin $3 \%$

- Jabučni ocat $3 \%$

- Morska sol $1 \%$

- Senf, 1 \%

- Mliječna komponenta: punomasno mlijeko u prahu, sirutka u prahu, kazein 1,5\%

- Vinska kiselina 0,1\%

- Destilirana voda 8,4\%

- Pulpa kivija $5 \%$

Uljnu fazu čini hladno prešano bučino ulje iz sorte Gleisdorf proizvedeno na Prehrambeno-tehnološkom fakultetu u Osijeku, a rafinirano suncokretovo ulje (linolni tip) dobiveno je iz Tvornice ulja Čepin. Jabučni ocat, morska sol i senf za proizvodnju salatne majoneze nabavljeni su u lokalnoj trgovini. Žumanjak jajeta kokoši nabavljen je od privatnog dobavljača te je priređen kao svježi. Ugljikohidrati glukoza i maltodekstrin nabavljeni su iz firme Claro-prom d.o.o., Zagreb, a saharoza iz Tvornice šećera Osijek. Vinska kiselina koja se dodaje u funkciji regulatora kiselosti majoneze nabavljena je od firme Alkaloid, Skoplje. Mliječnu komponentu čini punomasno mlijeko u prahu (proteini 26,3 \%, šećeri 39,8 \%, masti $26 \%)$ nabavljeno je iz firme Dukat d.d., a sirutka u prahu (mliječna mast u s.t. do $1 \%$, proteini $12-14 \%$, laktoza $73-75 \%$ ) iz firme Zdenka d.d. Kazein u prahu (masti 1,4\%, ugljikohidrati 9,9\%, vlakna 1,1\%, proteini $76,2 \%$, sol 1,89 \%) nabavljen je iz firme Glambia Nutritionals, Engleska. Voćna komponenta (pulpa kivija) pripremljena je na način da se kivi ogulio, izrezao na komadiće te usitnio mljevenjem kako bi se dobio homogeniziran uzorak.

\section{Priprema salatne majoneze}

Uzorci salatne majoneze s dodatkom pulpe kivija pripremljeni su na tradicionalan način u laboratorijskim uvjetima, pri sobnoj temperaturi u količini $200 \mathrm{~g}$ za pojedini uzorak. Proizvodnja salatne majoneze provedena je primjenom laboratorijskog homogenizatora model D-500 (Wiggenhauser, Njemačka-Malezija) sa područjem brzine rotora $10000-30000$ o/min. Kod izrade salatne majoneze korišten je sustav rotor/ stator Tip 1 (rotor SR20 i stator S20C). Kontrolni uzorak salatne majoneze pripremljen je sa $70 \%$ uljnom fazom koju čini mješavina rafiniranog suncokretovog ulja i hladno prešanog bučinog ulja te navedenim ostalim sastojcima (Tablica 1). Uzorci su pripremljeni tako da se izvažu potrebni sastojci te se dodaje $1 / 2$ suncokretovog ulja (60 g), zatim svježi žumanjak jajeta, jabučni ocat, voda i ostali sastojci, uključi se homogenizator i polagano se dodaje preostali dio suncokretovog i bučinog ulja te homogenizira 2 min kod brzine rotora $10000 / \mathrm{min}$. Priprema uzoraka salatne majoneze napravljena je pri sobnoj temperaturi svih sastojaka, a nakon izrade provedeno je mjerenje reoloških svojstava. Uzorci salatne majoneze pripremljeni su na isti način, samo što su se mijenjali pojedini 
sastojci ovisno od recepture pojedinog uzorka te procesni parametri homogenizacije. Kod izrade salatne majoneze sa rotor/stator sustavom Tip 2 korišten je rotor oznake ER30 i stator S30F.

Tablica 1. Osnovna receptura za pripremu salatne majoneze s dodatkom pulpe kivija (kontrolni uzorak)

\begin{tabular}{|l|c|c|}
\hline \multirow{2}{*}{ Sastojci } & \multicolumn{2}{|c|}{ Uzorak } \\
\hline Rafinirano suncokretovo ulje & Udio (\%) & Masa (g) \\
\hline Hladno prešano bučino ulje & 60 & 120 \\
\hline Svježi žumanjak jajeta kokoši & 10 & 20 \\
\hline Sirutka u prahu & 7 & 14 \\
\hline Saharoza & 1,5 & 3 \\
\hline Jabučni ocat & 3 & 6 \\
\hline Morska sol & 3 & 6 \\
\hline Senf & 1 & 2 \\
\hline Vinska kiselina & 1 & 2 \\
\hline Destilirana voda & 0,1 & 0,2 \\
\hline Ukupno & 8,4 & 16,8 \\
\hline
\end{tabular}

\section{Reološka svojstva}

Mjerenje reoloških svojstava ispitivanih uzoraka salatne majoneze (70 \%-tna uljna faza) provedeno je na rotacijskom viskozimetru, model DV-III+ Digital Rheometer-Brookfield Engineering Laboratories $(S A D)$, primjenom koncentričnih cilindara tipa SC4-28 i SC4-29. Viskozimetar je povezan sa računalom, opremljenim software-om Rheocalc 3.2 koje upravlja mjerenjem reoloških svojstava te provodi obradu izmjerenih podataka. Ispitivanje reoloških svojstava svježe pripremljenih uzoraka salatne majoneze provedeno je pri temperaturi 25 ${ }^{\circ} \mathrm{C}$. Održavanje konstantne temperature uzoraka tijekom mjerenja sa viskozimetrom postignuto je primjenom termostata model TC-501P, firme Brookfield. Mjerenjem je ispitivana ovisnost smičnog naprezanja $(\tau)$ i prividne viskoznosti $(\tau)$ o brzini smicanja (D) u periodu brzine smicanja 2,18 - 137,1 $\mathrm{s}^{-1}$ (uzlazno mjerenje) i $137,1-2,18 \mathrm{~s}^{-1}$ (povratno mjerenje). Na temelju ovako dobivenih eksperimentalnih vrijednosti određen je tip tekućine gdje je utvrđeno da su svi ispitivani uzorci salatne majoneze imali nenewtonovska svojstva, te pripadaju pseudoplastičnom tipu tekućina. Izračunate vrijednosti reoloških parametara koeficijenta konzistencije (k) $i$ indeksa tečenja $(n)$ dobivene su pomoću programa Microsoft Exel, uz primjenu metode linearne regresije.

Za izračun reoloških parametara koeficijenta konzistencije i indeksa tečenja primijenjen je Ostwald-Reinerov "stupnjeviti zakon":

$$
\tau=k \cdot D^{n}
$$

$\tau$ - smično naprezanje $(\mathrm{Pa})$

$$
\begin{gathered}
\mathrm{D} \text { - brzina smicanja }\left(\mathrm{s}^{-1}\right) \\
\mathrm{k} \text { - koeficijent konzistencije }\left(\mathrm{Pa} \cdot \mathrm{s}^{\mathrm{n}}\right) \\
\mathrm{n} \text { - indeks tečenja }(-)
\end{gathered}
$$

Izračunavanje parametra prividne viskoznosti uzoraka salatne majoneze provedeno je primjenom izraza:

$$
\mu=k \cdot D^{n-1}
$$

$\mu$ - prividna viskoznost (Pa.s)

\section{REZULTATI I RASPRAVA}

Rezultati ispitivanja utjecaja procesnih parametara homogenizacije (brzina rotora, vrijeme trajanja homogenizacije) te vrsta sustava rotor/stator (Tip 1, Tip 2) na reološka svojstva salatne majoneze s dodatkom pulpe kivija prikazani su u tablicama 2-4. Iz izračunatih vrijednosti reološkog parametra indeksa tečenja ( $n=$ 0-1) vidljivo je da ispitivana salatna majoneza pripada nenewtonovskim tekućinama, pseudoplastičnog tipa.

$\mathrm{U}$ tablici 2. prikazan je utjecaj brzine rotacije rotora tijekom 2 min homogenizacije (sustav rotor/stator Tip 1) na promjenu reoloških parametara salatne majoneze, mjereno pri sobnoj temperaturi $25^{\circ} \mathrm{C}$. Dobiveni rezultati pokazuju da se izradom salatne majoneze kod brzine rotora homogenizatora 10000 o/min proizvela majoneza sa prividnom viskoznošću ( $\mu$ ) 1,7098 (Pa.s) i konzistencija izražena koeficijentom konzistencije (k) 53,39 (Pa.sn) te indeks tečenja (n) 0,2589. Koristeći veću brzinu rotora $12000 \mathrm{o} / \mathrm{min}$ proizvedena je salatna majoneza s većom vrijednosti prividne viskoznosti 2,4790 (Pa.s) i koeficijenta konzistencije 77,23 (Pa.sn) te manjim indeksom tečenja 0,2504 . Razlog tome je taj što je primjenom veće brzine rotora došlo do stvaranja većeg broja kapljica ulja manjeg promjera što rezultira porastom viskoznosti i konzistencije ove emulzije ulje/voda. Daljnjim porastom brzine rotora na $15000 \%$ min tijekom proizvodnje ove salatne majoneze došlo je do stvaranja emulzije sa manjom prividnom viskoznosti (2,1781 Pa.s) i koeficijentom konzistencije $\left(54,45 \mathrm{~Pa} . \mathrm{s}^{\mathrm{n}}\right)$ u odnosu na primjenu brzine rotora $12000 \%$ min. Ova pojava možē se objasniti tako što se porastom brzine rotora homogenizatora do određene vrijednosti povećava viskoznost i konzistencija majoneze. Međutim, daljnjim porastom brzine rotora dolazi do narušavanja tj. razaranja stabilne strukture ove emulzije ulje/voda te dolazi do "razrjeđivanja” sustava. Veća stabilnost salatne majoneze postignuta je kod brzine rotora $15000 \%$ min u odnosu na $10000 \%$ min. 
Tablica 2. Utjecaj brzine rotacije rotora tijekom $2 \mathrm{~min}$ homogenizacije (sustav rotor/stator Tip 1) na reološke parametre salatne majoneze s dodatkom pulpe kivija, mjereno pri $25^{\circ} \mathrm{C}$

\begin{tabular}{|c|c|c|c|c|}
\hline Uzorak & $\begin{array}{c}\mu \\
\text { pri 103,9 s-1 } \\
(\mathbf{P a} . \mathbf{S})\end{array}$ & $\begin{array}{c}\mathbf{k} \\
\left(\mathbf{P a} . \mathbf{s}^{\mathbf{n}}\right)\end{array}$ & $\mathbf{n}$ & $\mathbf{R}^{\mathbf{2}}$ \\
\hline $10000 \% \min$ & 1,7098 & 53,39 & 0,2589 & 0,96402 \\
\hline $12000 \% \min$ & 2,4790 & 77,23 & 0,2504 & 0,99006 \\
\hline $15000 \% \min$ & 2,1781 & 54,45 & 0,3068 & 0,99122 \\
\hline
\end{tabular}

$\mu$ - prividna viskoznost pri brzini smicanja 103,9 $\mathrm{s}^{-1}$ (Pa.s)

k- koeficijent konzistencije (Pa. S $\left.^{n}\right)$

$n$ - indeks tečenja $(-)$

$R^{2}$ - koeficijent determinacije

U tablici 3 prikazan je utjecaj vremena trajanja homogenizacije $(1,2,3 \mathrm{~min})$, kod brzine rotora $10000 \% \mathrm{~min}$, primjenom sustava rotor/stator Tip 1, na reološka svojstva salatne majoneze izražena reološkim parametrima. Dobiveni rezultati pokazuju da se tijekom $1 \mathrm{~min}$ homogenizacije dobiju parametri prividna viskoznost 1,1089 (Pa.s) kod brzine smicanja 137,1 s-1, koeficijent konzistencije 33,93 (Pa.sn) te indeks tečenja 0,3048. Produženjem vremena trajanja homogenizacije kod izrade salatne majoneze sa 1 min na 2 min dobiva se emulzija veće viskoznosti 1,4177 (Pa.s) i konzistencije $52,71\left(P a . s^{n}\right)$, a manji indeks tečenja 0,2652. Daljnjim porastom vremena izrade salatne majoneze na 3 min došlo je do razaranja strukture što rezultira sniženjem viskoznosti 1,2828 (Pa.s) i konzistencije 42,32 (Pa.sn) te porasta indeksa tečenja 0,2895.

Tablica 3. Utjecaj vremena trajanja homogenizacije (sustav rotor/stator Tip 1) kod brzine rotora 10000 \%min na reološke parametre salatne majoneze s dodatkom pulpe kivija, mjereno pri $25^{\circ} \mathrm{C}$

\begin{tabular}{|c|c|c|c|c|}
\hline Uzorak & $\begin{array}{c}\mu \\
\text { pri 137,1 s-1 } \\
(\mathbf{P a} . \mathbf{S})\end{array}$ & $\begin{array}{c}\mathbf{k} \\
\left(\mathbf{P a} . \mathbf{s}^{\mathbf{n}}\right)\end{array}$ & $\mathbf{n}$ & $\mathbf{R}^{\mathbf{2}}$ \\
\hline $1 \mathrm{~min}$ & 1,1089 & 33,93 & 0,3048 & 0,98954 \\
\hline $2 \mathrm{~min}$ & 1,4177 & 52,71 & 0,2652 & 0,96941 \\
\hline $3 \mathrm{~min}$ & 1,2829 & 42,32 & 0,2895 & 0,96989 \\
\hline
\end{tabular}

Rezultati ispitivanja utjecaja primjene različitih sustava rotor/stator (Tip 1, Tip 2) na reološka svojstva salatne majoneze kod brzine rotora $10000 \%$ min i vremenu homogenizacije 2 min prikazani su u tablici 4 . Dobiveni rezultati ukazuju na pojavu da je primjenom sustava rotor/stator Tip 2 proizvedena stabilnija salatna majoneza s većom prividnom viskoznošću 3,3176 (Pa.s) i koeficijentom konzistencije 83,41 (Pa.sn) u odnosu na primjenu sustava rotor/stator Tip 1. Razlog tome može se objasniti konstrukcijskom izvedbom sustava rotor/stator, sustav Tip 2 ima takav izgled da se pri ispitivanoj brzini rotora postiže bolja disperzija kapljica ulja pri čemu nastaje veći broj kapljica ulja manjeg promjera, a to dovodi do veće viskoznosti i konzistencije sustava emulzije ulje/voda.

Tablica 4. Utjecaj tipa sustava rotor/stator tijekom homogenizacije kod brzine rotora 10000 \%min i vremena trajanja 2 min na reološke parametre salatne majoneze s dodatkom pulpe kivija, mjereno pri $25^{\circ} \mathrm{C}$

\begin{tabular}{|c|c|c|c|c|}
$\begin{array}{c}\text { Uzorak } \\
\text { (sustav rotor/ } \\
\text { stator }\end{array}$ & $\begin{array}{c}\boldsymbol{\mu} \\
\text { pri 77,92 s-1 } \\
\text { (Pa.s) }\end{array}$ & $\begin{array}{c}\mathbf{k} \\
\left(\mathbf{P a} . \mathbf{s}^{\mathbf{n}}\right)\end{array}$ & $\mathbf{n}$ & $\mathbf{R}^{\mathbf{2}}$ \\
\hline Tip 1 & 2,0781 & 54,17 & 0,2514 & 0,95704 \\
\hline Tip 2 & 3,3176 & 83,41 & 0,2597 & 0,98692 \\
\hline
\end{tabular}

Tip 1 (rotor SR20, stator S20C), Tip 2 (rotor ER30, stator S3OF)

Rezultati istraživanja utjecaja sastojaka (ugljikohidrata i mliječne komponente) na reološko ponašanje salatne majoneze $s$ dodatkom pulpe kivija izrađene kod brzine rotora $10000 \%$ min u vremenu 2 min, rotor/stator Tip 1, pri temperaturi mjerenja $25^{\circ} \mathrm{C}$ prikazani su u tablicama 5 i 6.

Utjecaj vrste ugljikohidrata (glukoza, saharoza, maltodekstrin) na reološka svojstva izražena reološkim parametrima salatne majoneze prikazan je u tablici 5. Dobiveni rezultati pokazuju da salatna majoneza izrađena s maltodekstrinom ima najnižu vrijednost prividne viskoznosti 4,179 (Pa.s) i koeficijent konzistencije 80,21 (Pa.sn) te najveću vrijednost indeksa tečenja 0,2761. Korištenjem glukoze (monosaharid) kod izrade salatne majoneze dobiva se veća prividna viskoznost i koeficijent konzistencije te manji indeks tečenja u odnosu na primjenu maltodekstrina. Izradom salatne majoneze sa saharozom (disaharid) postižu se reološka svojstva s najvećom vrijednosti prividne viskoznosti 4,391 (Pa.s) i koeficijentom konzinstencije 113,98 (Pa.sn) te najnižim indeksom tečenja 0,2021.

Tablica 5. Utjecaj vrste ugljikohidrata na reološke parametre salatne majoneze s dodatkom pulpe kivija, izrađene kod $10000 \%$ min i vremenu 2 min sa sustavom rotor/stator Tip 1, mjereno pri $25^{\circ} \mathrm{C}$

\begin{tabular}{|c|c|c|c|c|}
\hline Uzorak & $\begin{array}{c}\boldsymbol{\mu} \\
\text { pri 59,22 } \mathbf{s}^{-1} \\
(\mathbf{P a} . \mathbf{s})\end{array}$ & $\begin{array}{c}\mathbf{k} \\
\left(\mathbf{P a} . \mathbf{s}^{\mathbf{n}}\right)\end{array}$ & $\mathbf{n}$ & $\mathbf{R}^{\mathbf{2}}$ \\
\hline Glukoza & 4,332 & 106,19 & 0,2161 & 0,99383 \\
\hline Saharoza & 4,391 & 113,98 & 0,2021 & 0,98699 \\
\hline Maltodekstrin & 4,179 & 80,21 & 0,2761 & 0,98899 \\
\hline
\end{tabular}

U tablici 6 prikazani su rezultati ispitivanja utjecaja mliječne komponente (punomasno mlijeko u prahu, sirutka u prahu, kazein u prahu) na reološke parametre salatne majoneze s dodatkom pulpe kivija. Uzo- 
rak salatne majoneze izrađen sa kazeinom ima vrijednost prividne viskoznosti 2,488 (Pa.s) kod brzine smicanja 59,22 (s-1) i koeficijent konzistencije 53,795 $\left(P a . s^{n}\right)$ te indeks tečenja 0,2353. Primjenom punomasnog mlijeka u prahu došlo je do malog porasta prividne viskoznosti 2,692 (Pa.s) i koeficijenta konzistencije 56,39 (Pa.sn) salatne majoneze. Kod salatne majoneze izrađene sa sirutkom u prahu ostvarena je veća vrijednost prividne viskoznosti i koeficijenta konzistencije te niži indeks tečenja u odnosu na primjenu ispitivanih mliječnih sastojaka.

Tablica 6. Utjecaj mliječne komponente na reološke parametre salatne majoneze s dodatkom pulpe kivija, izrađene kod $10000 \%$ min i vremenu 2 min sa sustavom rotor/stator Tip 1, mjereno pri $25^{\circ} \mathrm{C}$

\begin{tabular}{|c|c|c|c|c|}
\hline Uzorak & $\begin{array}{c}\mu \\
\text { pri } 59,22 \mathbf{s}^{-1} \\
(\mathbf{P a} . \mathbf{s})\end{array}$ & $\begin{array}{c}\mathbf{k} \\
\left(\mathbf{P a} . \mathbf{s}^{\mathbf{n}}\right)\end{array}$ & $\mathbf{n}$ & $\mathbf{R}^{2}$ \\
\hline $\begin{array}{c}\text { Punomasno } \\
\text { mlijeko u prahu }\end{array}$ & 2,692 & 56,39 & 0,2662 & 0,97803 \\
\hline Sirutka u prahu & 4,391 & 113,98 & 0,2021 & 0,98699 \\
\hline Kazein & 2,488 & 53,795 & 0,2353 & 0,95225 \\
\hline
\end{tabular}

\section{ZAKLJUČCI}

Ispitivani uzorci salatne majoneze $s$ dodatkom pulpe kivija pripadaju nenewtonovskim sustavima, pseudoplastičnog tipa tekućine. Primjenom voćne komponente pulpe kivija postigao se blago voćni okus salatne majoneze. Hladno prešano bučino ulje u uljnoj fazi osigurava oksidacijsku stabilnost (održivost) i povećava nutritivnu vrijednost salatne majoneze. Veća prividna viskoznost i konzistencija salatne majoneze s dodatkom pulpe kivija ostvarena je izradom kod brzine rotacije rotora $10000 \% \mathrm{~min}$ tijekom 2 minute homogenizacije i primjenom sustava rotor/stator Tip 2. Najprihvatljivija receptura salatne majoneze što se tiče veće prividne viskoznosti i konzistencije, a manjeg indeksa tečenja postignuta je primjenom saharoze i proteina sirutke u prahu.

\section{LITERATURA}

Abu-Jdayil, B. (2003): Modelling the time-dependent rheological behavior of semisolid foodstuffs. J. Food Eng. 57, 97-102.

Akhtar, M., J. Stenzel, B.S. Murray, E. Dickinson (2005): Factors affecting the perception of creaminess of oil-inwater emulsions. Food Hydrocolloids 19, 521-526.

Batista, A.P., A. Raymundo, i. Sousa, J. Empis (2006): Rheological characterization of coloured oil-in-water food emulsions with lutein and phycocyanin added to the oil and aqueous phases. Food Hydrocolloid 20, 44-52.
Castellani, O., C. Belhomme, E. David-Briand, C. GuerinDubiard, M. Anton (2006): Oil-in-water emulsion properties and interfacial characteristcs of hen egg yolk phosvitin. Food Hydrocolloids 20, 35-43.

Cristina, I., M. Aizpurua, A. Tenuta-Filho (2005): Oxidation of cholesterolin mayonnaise during storage. Food Chem. 89, 611-615.

Dybowska, B.E. (2008): Properties of milk protein concentrate stabilized oil-in-water emulsions. Journal of Food Engineering 88, 507-513.

Državni zavod za normizaciju i mjeriteljstvo (1999): Pravilnik o temeljnim zahtjevima za jestiva ulja i masti, margarine i njima sličnim proizvodima, majoneze, umake, preljeve, salate i ostale proizvode na bazi jestivih ulja i masti. Narodne novine 39/99.

Franco, J.M., A. Guerrero, C. Gallegos (1995): Rheology and processing of salad dressing emulsions. Rheologica Acta 34, (6), 513-524.

Guilmineau, F., U. Kulozik (2007): Influence of a thermal treatment on the functionality of hens egg yolk in mayonnaise. J. Food Eng. 78, 648-654.

Hasenhuettl G. L., R. W. Hartel (2008): Food emulsifiers and their applications. Springer Science.

Juszczak, L., T. Fortuna, A. Kosla (2003): Sensory and rheological propoerties of Polish commercial mayonnaise. Nahrung/Food 47, 232-235.

Kiosseoglou, V. (2003): Egg yolk protein gels and emulsions. Current Opinion in Colloid and Interface Science 8 , 365-370.

Kostyra, E., N. Barylko-Pikielna (2007): The effect of fat levels and guar gum addition in mayonnaise-type emulsions on the sensory perception of smoke-curing flavour and salty taste. Food Qual. Prefer. 18, 872-879.

Laca, A., M.C. Saenz,B. Paredes, M. Diaz (2010): Rheological properties, stability and sensory evaluation of lowcholesterol mayonnaises prepared using egg yolk granules as emulsifying agent. Journal of Food Engineering 97, 243-252.

McClements, D.J., K. Demetriades (1998): An integrated approach to the development of reduced-fat food emulsions. Critical Reviews in Food Science and Nutrition, 38, 511-536.

Mezger T. G. (2002): The rheology handbook. Vincentz, Hannover, Germany.

Narsimhan, G., Z. Wang, (2008): Guidelines for processing emulsion-based foods. In: Hasenhuettl, G.L., Hartel, R.W. (Eds.), Food Emulsifiers and their Applications. Springer Science+Business Media, USA, 349-389.

Raikos, V., A. McDonagh, V. Ranawana, G. Duthie (2016): Processed beetroot (Beta vulgaris L.) as a natural antioxidant in mayonnaise: Effects on physical stability, texture and sensory attributes. Food Science and Human Wellness 5, 191-198. 
Ruiling, S., L. Shuangqun, D. Jilin (2011): Application of oat dextrine for fat substitute in mayonnaise. Food Chemistry $126,65-71$.

Štern, P., H. Valentova, J. Pokorny (2001): Rheological properties and sensory texture of mayonnaise. Eur. J. Lipid Sci. Technol. 103, 23-28.

Wendin, K., G. Hall (2001): Influences of fat, thickener and emulsifier contents on salad dressing: static and dynamic sensory and rheological analyses. Lebensm.-Wiss. u.-
Technol. 34, 222-233.

Wendin, K., M. Risberg Ellekjar, R. Solheim (1999): Fat Contetnt and Homogenization Effects on Flavour and Texture of Mayonnaise with Added Aroma. Lebensm.Wiss. u.- Technol. 32, 377-383.

Xiong, R., G. Xie, A.S. Edmondson (2000): Modelling the $\mathrm{pH}$ of mayonnaise by the ratio of egg to vinegar. Food Control 11, 49-56.

Dostavljeno: 20.2.2018.

Prihvaćeno 5.3.2018.

\section{Rheologieal properties of salad mayonnaise with added kiwi fruit pulp}

\section{SUMMARY}

In this paper, we examined the effect exerted by various process parameters of homogenisation and different types of rotor-stator system on the rheological properties of salad mayonnaise with added kiwi fruit pulp. We also examined the effect of salad mayonnaise ingredients on the change in rheological properties. The oil phase of salad mayonnaise was a mixture of refined sunflower and cold pressed pumpkin seed oil. The types of carbohydrates we used included glucose, sucrose and maltodextrin. The dairy component of salad mayonnaise consisted of whole milk, whey and casein. The samples of salad mayonnaise were prepared by adding a fresh chicken egg yolk. The process of salad mayonnaise homogenisation was carried out at various rotor speeds and different durations of making the mayonnaise. The measurement of rheological properties was performed using a rotational viscosimeter at the temperature of $25{ }^{\circ} \mathrm{C}$. We used the received experimental results to calculate rheological parameters which included consistency coefficient, flow behaviour index and apparent viscosity. The results of our research indicated that process parameters of homogenisation and certain ingredients of salad mayonnaise both affect its rheological properties. When using whey powder and sucrose sugar we obtained higher values for rheological parameters of consistency coefficient and apparent viscosity, and a lower flow behaviour index.

Key words: salad mayonnaise, rheological properties, homogenisation process, mayonnaise ingredients, kiwi fruit pulp

\section{Rheologische Eigenschaften der Salatmayonnaise mit Zugabe der Kiwifruchtmark}

\section{ZUSAMMENFASSUNG}

In der vorliegenden Arbeit wurden der Einfluss von Prozessparametern der Homogenisierung und der Typ des Systems Rotor/Stator auf rheologische Eigenschaften der Salatmayonnaise mit Zugabe des Kiwifruchtmarks untersucht. Darüber hinaus wurde auch der Einfluss der Zusammensetzung der Salatmayonnaise auf Änderung von rheologischen Eigenschaften untersucht. Die Ölphase der Salatmayonnaise besteht aus einer Mischung von raffiniertem Sonnenblumenöl und kaltgepresstem Kürbiskernöl. Als Kohlenhydraten wurden Glukose, Saccharose und Maltodextrin verwendet. Die Milchkomponente der Salatmayonnaise besteht aus Vollmilch, Molke und Kasein. Die Proben der Salatmayonnaise wurden mit frischem Eigelb des Hühnereis vorbereitet. Der Prozess der Homogenisierung der Salatmayonnaise wurde mit unterschiedlichen Drehgeschwindigkeiten des Rotors und unterschiedlichen Zeitdauern der Zubereitung der Mayonnaise durchgeführt. Die Messung der rheologischen Eigenschaften wurde an einem Rotationsviskosimeter bei einer Temperatur von $25{ }^{\circ} \mathrm{C}$ durchgeführt. Aus den gewonnenen Ergebnissen der Untersuchung wurden rheologische Parameter wie Konsistenzkoeffizient, Fließindex und Scheinviskosität ermittelt. Die Ergebnisse der Untersuchung haben ergeben, dass die Prozessparameter der Homogenisierung wie auch einzelne Inhaltsstoffe der Salatmayonnaise ihre rheologische Eigenschaften beeinflussen. Durch Verwendung von Molkenpulver und Saccharose wurden höhere Werte der rheologischen Parameter des Konsistenzkoeffizienten und der Scheinviskosität und der niedrigere Fließindex erreicht.

Schlüsselwörter: Salatmayonnaise, rheologische Eigenschaften, Prozess der Homogenisierung, Inhaltsstoffe der Mayonnaise, Kiwifruchtmark 


\section{Características reológicas de la mayonesa de ensalada con la añadidura de pulpa de kiwi}

\section{RESUMEN}

En este trabajo fue investigada la influencia de los parámetros del proceso de la homogenización y del tipo del sistema rotorlestator sobre las características reológicas de la mayonesa de ensalada con la añadidura de pulpa de kiwi. También fue investigada la influencia de la composición de la mayonesa de ensalada sobre el cambio de las características reológicas. La fase dispersa de la mayonesa de ensalada fue compuesta del aceite de girasol refinado y del aceite de semilla de calabaza prensado en frío. De los carbohidratos fueron usadas la glucosa, la sacarosa y la maltodextrina. El componente de leche de la mayonesa de ensalada fue compuesta de la leche, del suero de leche y de la caseína. Las muestras de la mayonesa de ensalada fueron preparadas con la yema fresca del huevo de gallina. El proceso de la homogenización de la mayonesa de ensalada fue hecho bajo varias velocidades del rotor y tiempos de la preparación de la mayonesa. La medición de las características reológicas fue hecha en el viscosímetro rotacional bajo la temperatura de $25{ }^{\circ} \mathrm{C}$. De los resultados del análisis fueron calculados los parámetros reológicos como el coeficiente de coherencia, el índice de flujo y la viscosidad aparente. Los resultados de la investigación mostraron que los parámetros del proceso de la homogenización y varios ingredientes de la mayonesa de ensalada influyen sobre sus características reológicas. Con el uso del suero de leche en polvo y el azúcar la sacarosa fueron obtenidos los valores más altos de los parámetros reológicos - del coeficiente de coherencia y de la viscosidad aparente y el índice de fujo más bajo.

Palabras claves: mayonesa de ensalada, características reológicas, proceso de homogenización, ingredientes de mayonesa, pulpa de kiwi

\section{Caratteristiche reologiche della maionese da insalata con aggiunta di polpa di kiwi}

\section{RIASSUNTO}

In questo studio è stata esaminata l'incidenza dei parametri di processo dell'omogeneizzazione e il tipo del sistema rotore/statore sulle caratteristiche reologiche della maionese da insalata con aggiunta di polpa di kiwi. Ė stata esaminata, inoltre, l'incidenza della composizione della maionese da insalata sulla modificazione delle caratteristiche reologiche. La fase oleosa della maionese da insalata è costituita da una miscela di olio di girasole raffinato e di olio di zucca spremuto a freddo. Tra i carboidrati impiegati, spiccano il glucosio, il saccarosio e la maltodestrina. La componente di latte della maionese da insalata è costituita da latte intero, siero del latte e caseina. I campioni di maionese da insalata sono stati preparati con tuorli freschi di uova di gallina. II processo di omogeneizzazione della maionese da insalata è stato eseguito a diverse velocità e con diversi tempi. La misurazione delle caratteristiche reologiche è stata eseguita mediante viscosimetro a rotazione alla temperatura di $25^{\circ} \mathrm{C}$. Dai risultati ottenuti sono stati calcolati i seguenti parametri reologici: coefficiente di consistenza, indice di liquidità e viscosità apparente. I risultati della ricerca hanno dimostrato che i parametri di processo dell'omogeneizzazione e alcuni ingredienti della maionese da insalata incidono sulle sue caratteristiche reologiche. Impiegando siero del latte in polvere e saccarosio, i valori di alcuni parametri reologici, come il coefficiente di consistenza e la viscosità apparente, sono risultati maggiori, mentre l'indice di liquidità è risultato inferiore rispetto a quelli rilevati.

Parole chiave: maionese da insalata, caratteristiche reologiche, processo di omogeneizzazione, ingredienti della maionese, polpa del kiwi



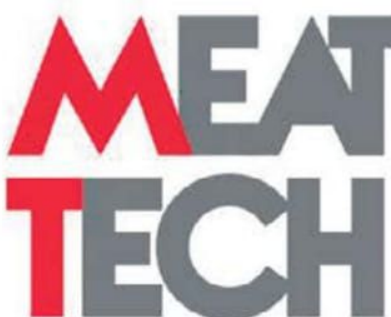

Processing \& Packaging for the Meat Industry

Fiera Milano, Milan - Italy May 29 - June 12018

\section{SOLUTIONS FOR YOUR BUSINESS}

